\title{
Manajemen Anestesi untuk Awake Craniotomy pada Space Occupying Lesion Lobus Frontalis Kiri
}

\author{
Ferry Ferdyansyah, M. Sofyan Harahap \\ Departemen Anestesiologi \& Terapi Intensif Fakultas Kedokteran Universitas Diponegoro-RSUP Dr. Kariadi \\ Semarang
}

\begin{abstract}
Abstrak
Tumor intrakranial adalah suatu lesi ekspansif yang membentuk massa dalam ruang tengkorak. Kami melaporkan manajemen anestesi pada pasien dengan tumor intrakranial yang menjalani prosedur awake craniotomy. Seorang laki-laki berumur 39 tahun, berat badan $60 \mathrm{~kg}$ dengan riwayat epilepsi ditemukan space occupying lession pada lobus frontalis kiri setelah dilakukan CT-scan kepala. Prosedur awake craniotomy untuk pengangkatan tumor dilakukan karena lokasi tumor berada di dekat area Broca. Awake craniotomy dilakukan dengan kombinasi anestesi intravena (i.v) dexmedetomidin dan blok scalp. Premedikasi midazolam $2 \mathrm{mg}$ i.v dan oksigenasi 3 liter/menit nasal diberikan dari awal proses operasi. Pasien diberikan dexmedetomidine loading dose $1 \mathrm{mcg} / \mathrm{kgBB}$ dalam 15 menit dan fentanyl $1 \mathrm{mcg} / \mathrm{kgBB}$ i.v sebelum dilakukan blok scalp dengan injeksi bupivacain isobarik 0,5\% dicampur pehacain 1:1, total $40 \mathrm{ml}$ untuk kedua sisi kepala. Infiltrasi larutan bupivacain-pehacain tambahan diberikan 2,5 $\mathrm{ml}$ pada setiap titik pin holder fiksasi kepala dipasang. Pemeliharaan anestesi dijaga dengan infus kontinyu dexmedetomidin $0,5-0,7 \mathrm{mcg} / \mathrm{KgBB} / \mathrm{jam}$ i.v selama pasien terbangun dan propofol $0,05-0,1 \mathrm{mg} / \mathrm{kgBB} / \mathrm{menit}$ i.v ditambahkan apabila pasien ditidurkan. Mannitol $1 \mathrm{~g} / \mathrm{kgBB}$ i.v diberikan 15 menit sebelum duramater dibuka. Proses kraniotomi berjalan 4 jam. Selama operasi berlangsung pasien tidak mengalami perubahan hemodinamik yang signifikan, tekanan darah rata-rata 95-69 mmHg, laju nadi 56-63 x/mnt, $\mathrm{SpO}_{2} 100 \%$ dengan VAS 0-1. Pasca operasi, pasien stabil dan pindah ke ruangan setelah diobservasi selama 1 jam di ruang pemulihan.
\end{abstract}

Kata kunci : Awake craniotomy, blok scalp, dexmedetomidin, propofol

JNI 2018;7(3): 150-56

\section{Anesthesia Management for Awake Craniotomy on Left Frontal Lobe Solid Occupiying Lesion}

\begin{abstract}
Intracranial tumors are an expansive lesion that forms masses in the skull space. We report anesthesia management in patients with intracranial tumors who undergo awake craniotomy procedures. A 39-year-old male weighing $60 \mathrm{~kg}$ with a history of epilepsy found space occupying lession in the left frontal lobe after a head CT scan. The awake craniotomy procedure for removal of the tumor is done because the location of the tumor is near the Broca area. Awake craniotomy is performed with a combination of dexmedetomidine intravenous (i.v) and scalp block. Premedication with $2 \mathrm{mg}$ midazolam i.v and oxygenation of 3 liters / minute nasal was given from the beginning of the surgery. The patient was given dexmedetomidine loading dose of $1 \mathrm{mcg} / \mathrm{kg}$ in 15 minutes and fentanyl $1 \mathrm{mcg} /$ $\mathrm{kg}$ i.v before scalp block was done with $0.5 \%$ isobaric bupivacain injection mixed with 1 : 1 Pehacain, a total of 40 $\mathrm{ml}$ for both sides of the head. Additional infiltration of bupivacain-pehacain solution was given $2.5 \mathrm{ml}$ at each point the head fixation pin holder was installed. Maintenance of anesthesia is maintained with a continuous infusion of dexmedetomidine $0.5-0.7 \mathrm{mcg} / \mathrm{Kg} / \mathrm{h} \mathrm{i.v} \mathrm{as} \mathrm{long} \mathrm{as} \mathrm{the} \mathrm{patient} \mathrm{is} \mathrm{awake} \mathrm{and} \mathrm{propofol} 0.05-0.1 \mathrm{mg} / \mathrm{kg} / \mathrm{minute} \mathrm{i} . \mathrm{v}$ is added when the patient is put to sleep. Mannitol $1 \mathrm{~g} / \mathrm{kg}$ i.v is given, 15 minutes before the duramater is opened. The craniotomy process runs 4 hours. During surgery, the patient does not experience significant hemodynamic changes, Mean Blood Pressure is 95-69 mmHg, heart rate 56-63 x/min, $\mathrm{SpO}_{2} 100 \%$ with VAS 0-1. After surgery, the patient was stable and moved to the ward after being observed for 1 hour in the recovery room.
\end{abstract}

Key words: Awake craniotomy, scalp block, dexmedetomidine, propofol 


\section{Pendahuluan}

Tumor intrakranial adalah suatu lesi ekspansif yang bersifat jinak (benigna) ataupun ganas (maligna), membentuk massa dalam ruang tengkorak kepala yang membutuhkan suatu pengertian mengenai patofisiologi dari penekanan tekanan intrakranial, pengaturan dan pemeliharaan perfusi intraserebral. Kami melaporkan manajemen anestesi pada pasien laki laki dengan tumor intrakranial yang menjalani prosedur awake craniotomy. Awake Craniotomy adalah teknik yang penting digunakan untuk eksisi tumor otak pada area korteks bahasa dan operasi epilepsi. Teknik ini bermanfaat dalam meningkatkan keberhasilan pengangkatan lesi tumor, meningkatkan kelangsungan hidup pasca operasi $^{1}$, memberikan kesempatan mapping cortex dan subcortex ${ }^{2}$, untuk meminimalkan kerusakan korteks bahasa dan meminimalkan disfungsi neurologis pasca operasi. ${ }^{3}$ Keunggulan lainnya termasuk waktu rawat inap yang lebih pendek, maka biaya perawatan berkurang, dan menurunkan insiden komplikasi pasca operasi seperti mual dan muntah.

Istilah awake craniotomy sebenarnya menyesatkan, karena pasien tidak sepenuhnya terjaga untuk keseluruhan prosedur. Pasien diperlukan untuk sepenuhnya bangun dan kooperatif selama tes neurologik, selama prosedur pemetaan dan selama reseksi lesi terjadi. ${ }^{4}$ Teknik anestesi umum yang digunakan adalah sedasi saja atau anestesi umum, dan membangunkan pasien untuk pemetaan kortikal dan reseksi, dengan opsi pasien ditidurkan kembali dalam anestesi umum untuk penutupan.

\section{Kasus}

Seorang pasien laki-laki 39 tahun, dengan berat badan $60 \mathrm{~kg}$, didiagnosis adanya massa intracranial pada kortikal lobus frontal kiri dengan riwayat kejang berulang sehingga didiagnosis mengidap epilepsi. Pasien dilakukan kraniotomi untuk mengeluarkan massa.

Pemeriksaan Fisik

Tekanan darah saat masuk kamar operasi 122/76
$\mathrm{mmHg}$, laju nadi $66 \mathrm{kali} / \mathrm{menit}$, laju nafas $15 \mathrm{kali} /$ menit, suhu $36,7^{\circ} \mathrm{C}$, dan GCS E4 V5 M6. Mata pupil isokor, Mallampati II, pemeriksaan jantung dan paru dalam batas normal, dan fungsi motorik dalam batas normal.

\section{Pemeriksaan Laboratorium}

Dari pemeriksaan darah rutin $\mathrm{Hb} 15 \mathrm{gr} / \mathrm{dL}$, hematokrit $35 \%$, leukosit $10.500 / \mathrm{L}$, trombosit 256.000/L dengan hasil laboratorium kimia darah lain dalam batas normal. Hasil elektrokardiografi irama normosinus dan hasil thorax foto sehari sebelum operasi ada infiltrat di lapang paru kiri bawah curiga bronkopneumonia. Hasil CT scan kepala memberi kesan: tampak massa solid pada kortikal lobus frontal kiri ukuran 2,2 x 2,4 x 3,1 $\mathrm{cm}$ dan tidak tampak peningkatan intrakranial.

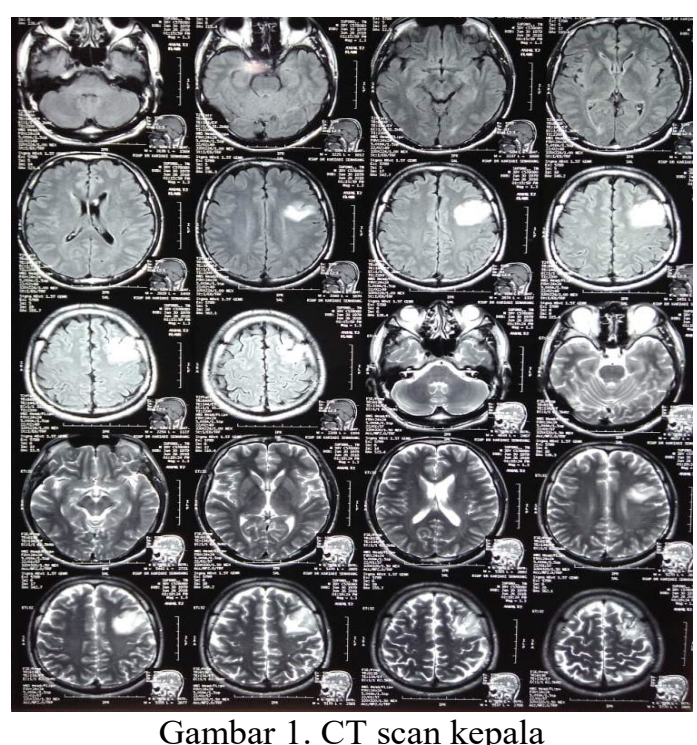

\section{Pengelolaan Anestesi}

Pasien diberikan premedikasi ondansetron 4 $\mathrm{mg}$ intravena (i.v), dexametason $10 \mathrm{mg}$ iv dan midazolam $2 \mathrm{mg}$ iv. Di kamar operasi, pasien diberi oksigen dengan nasal kanul 3 Liter/menit dan dexmedetomidine loading dose $1 \mathrm{mcg} / \mathrm{kgBB}$ iv diberikan dalam waktu 15 menit dengan syringe pump. Pasang jalur infus kedua dengan abocath $20 \mathrm{G}$ dan pasang kateter urin dilakukan setelah loading dexmedetomidine selesai, kemudian lanjutkan pemberian dexmedetomidine dengan dosis rumatan 0,5 - 0,7 $\mathrm{mcg} / \mathrm{kgBB} / \mathrm{jam}$. Pasien 
diberikan fentanyl $1 \mathrm{mcg} / \mathrm{kgBB}$ dan parasetamol $1 \mathrm{~g}$ infus lalu dilakukan scalp block dengan injeksi bupivacain isobarik $0,5 \%$ dicampur pehacain dengan perbandingan 1:1, dengan total $40 \mathrm{ml}$ larutan campuran bupivacain-pehacain untuk kedua sisi kepala. Saat pemasangan elektrodaelektroda electromyography (EMG) pasien diberikan propofol loading $20 \mathrm{mg}$ dilanjutkan rumatan $0,05 \mathrm{mg} / \mathrm{kgBB} / \mathrm{menit} \mathrm{IV}$ dengan syring pump. Lalu propofol dihentikan setelah semua elekroda terpasang. Fentanyl $1 \mathrm{mcg} / \mathrm{kgBB} / \mathrm{menit}$ diberikan intermiten setiap 1 jam. Injeksi infiltrasi larutan bupivacain-pehacain tambahan diberikan 2,5-3 ml pada setiap titik pin holder tempat fiksasi kepala dipasang. Ramsay score antara 3 dan 4 dipertahankan dengan titrasi dari dosis dexmedetomidine 0,4 sampai dengan $0,7 \mathrm{mcg} /$ $\mathrm{kgbb} /$ menit. Pemeriksaan elektrofisiologi selama operasi dapat berjalan baik dan dilakukan oleh ahli neurologi, demikian juga tes bicara, mengartikan gambar dan tes motorik dapat dilakukan dengan baik. Pasca pemetaan dan eksisi tumor pasien ditidurkan dengan menjalankan kembali rumatan propofol $0,05-0,1 \mathrm{mg} / \mathrm{kgBB} /$ menit IV dengan syring pump. Proses kraniotomi berjalan 4 jam. Saat operasi berlangsung, pasien tidak mengalami perubahan hemodinamik yang signifikan. Selama operasi, tekanan darah rata-rata (MAP) pasien berada dikisaran $95-69 \mathrm{mmHg}$, laju nadi 56-63 $\mathrm{x} / \mathrm{mnt}$ dan $\mathrm{SpO}_{2} 100 \%$ dengan perdarahan sekitar $300 \mathrm{ml}$. Pasien tidak mengeluh selama operasi dengan visual analog scale (VAS) $0-1$.

\section{Pengelolaan Pascabedah}

Setelah operasi, kondisi pasien stabil dengan Glasgow Coma Scale 15, tanda vital dalam batas normal dan VAS 0-1 di ruang pulih sadar, kemudian dipindahkan ke ruangan perawatan biasa setelah di observasi selama 1 jam di ruang pulih sadar.

\section{Pembahasan}

\section{Obat-obat Intravena}

\section{Dexmedetomidin}

Dexmedetomidin adalah suatu super-selektif alpha-2 adrenegik agonis dengan perbandingan alpha-2:alpha-1 sebesar 1600:1. Mempunyai efek sedatif juga analgesik, dan anesthesia sparring effect-nya menurunkan kebutuhan akan obat anestesi intravena, obat anestesi inhalasi, dan obat analgetik narkotik lainnya. Menurunkan tekanan darah dan denyut jantung. Efek sedasi tidak disertai dengan efek depresi nafas, dan pasien mudah dibangunkan dan kooperatif. Aktivasi reseptor alpha-2 dari dexmetomidin dapat menimbulkan sedasi dan ansiolisis, analgesia, penurunan katekolamin plasma, mempunyai efek hipotensi dan bradikardi. Efek dexmedetomidin pada aliran darah otak pada binatang percobaan menunjukkan adanya penurunan aliran darah otak sampai $45 \%$, tidak mempunyai pengaruh pada metabolisme otak, vasokonstriksi arteri dan vena, mengurangi efek vasodilatasi akibat hipoksia-hiperkapni. Pada penelitian manusia dengan transcranial dopler (TCD) menunjukkan adanya penurunan velositas rerata aliran darah otak dengan meningkatnya konsentrasi plasma dexmedetomidin. Index pulsatilitas meningkat pada konsentrasi tinggi dexmedetomidin yang menunjukkan adanya peningkatan resistensi pembuluh darah otak. Penelitian pada binatang menujukkan bahwa tekanan intrakranial tidak berubah walaupun ada peningkatan tekanan darah. Akan tetapi, tekanan intrakranial akan menurun bila sebelumnya ada peningkatan tekanan intrakranial. Penelitian pada manusia menunjukkan dexmedetomidin tidak mempengaruhi tekanan cairan serebrospinal lumbal pada pasien yang sedang mengalami reseksi tumor hipofise transpenoidal.

Efek neuroproteksi dexmedetomidin disebabkan karena menghambat iskemia yang diakibatkan pelepasan norepinefrin. Dexmedetomidin menurunkan level norepinefrin saat bangun dari anestesi (2 sampai 3 kali lebih rendah daripada plasebo). Dexmedetomidin mencegah kematian sel neuron setelah iskemi fokal dan daerah yang mengalami iskemik turun $40 \%$ dibandingkan dengan plasebo. Dexmedetomidin meningkatkan pembuangan glutamin melalui metabolisme oksidatif pada astrosit. ${ }^{5}$ Dexmedetomidin sebagai alpha-2 adrenoreseptor agonis memiliki beberapa keuntungan sebagai neuroprotektan dilihat dari pengaruhnya terhadap penurunan kadar glutamat. ${ }^{6}$ Alpha-2 agonis menurunkan konsumsi oksigen perioperatif. Obat sedatif yang ideal adalah 
mampu menurunkan $\mathrm{CMRO}_{2}$, menurunkan tekanan intrakranial tanpa menurunkan tekanan perfusi otak, mempertahankan autoregulasi serebral dan reaktivitas pembuluh darah terhadap $\mathrm{CO}_{2}$, mula kerja cepat dan lancar, mudah mengendalikan kedalaman dan lamanya sedasi, pada dosis therapeutic window dapat dilakukan evaluasi status neurologis dan komplikasi. Dexmedetomidin mempunyai sifat: sedasi reversibel tanpa depresi nafas, analgesia, anesthetic sparing effect, kardiovaskular stabil, mempunyai efek minimal pada tekanan intrakranial, mempunyai efek neuroproteksi, pasien cepat bangun. Secara teori dexmedetomidin menguntungkan untuk sedasi selama dan pascabedah pada pasien dengan kelainan intraserebral. Efek samping dexmedetomidin adalah hipotensi, hipertensi selintas, bradikardi, mulut kering, efek amnesi sedikit. Melihat efek dexmedetomidin pada dinamika serebral, kiranya dapat dipertimbangkan pemakaian dexmedetomidin untuk anestesi bedah saraf dan operasi lain dengan kelainan serebral. ${ }^{5}$

\section{Propofol}

Propofol telah digunakan secara luas dalam neuroanestesi begitu juga untuk awake craniotomy pada saat periode pasien perlu ditidurkan. Propofol mudah dititrasi untuk mendapatkan efek sedatif, pemulihan cepat, menurunkan metabolisme otak (cerebral metabolic rate for oxygen $/ \mathrm{CMRO}_{2}$ ), menurunkan tekanan intrakranial (intracranial pressurel ICP), mempunyai gambaran anti convulsan dan antiemetik. Walaupun propofol memiliki efek menurunkan tekanan perfusi otak (cerebral perfusion pressure/CPP) dengan cara menurunkan tekanan darah, tetapi efek hemodinamik yang tidak menyenangkan tersebut dapat dicegah dengan menghindari efek konsentrasi puncak. Efek propofol terhadap metabolime otak dan aliran darah otak (cerebral blood flow/CBF) sama seperti golongan barbiturat. Pada penelitian manusia, juga diperlihatkan bahwa propofol menurunkan CBF dan metabolisme otak. Pada pasien dengan cedera otak, anestesia dengan propofol akan menurunkan CPP, ICP dan CBF. Reaktivitas perfusi serebral terhadap $\mathrm{CO}_{2}$ tetap ada. Profopol menurunkan CBF (sebanyak 30\%),
$\mathrm{CMRO}_{2}(30 \%)$, dan ICP, tetapi CPP juga menurun disebabkan oleh propofol yang mempunyai efek menurunkan tekanan darah yang hebat. Penelitian lain menyatakan bahwa propofol bisa menurunkan atau tidak mengakibatkan perubahan pada ICP. Dengan infus kontinyu, CPP dipertahankan adekuat sehingga total intravenous anesthesia (TIVA) dengan propofol cukup menyenangkan. Seperti halnya hipnotik sedatif yang lain, depresi susunan saraf pusat terjadi bergantung pada dosis. $^{5}$

\section{Fentanyl}

Dosis kecil narkotik mempunyai efek kecil pada $\mathrm{CBF}$ dan $\mathrm{CMRO}_{2}$, sedangkan pada dosis besar menurunkan $\mathrm{CBF}$ dan $\mathrm{CMRO}_{2}$. Tidak mempengaruhi autoregulasi dan reaktivitas pembuluh darah otak terhadap $\mathrm{CO}_{2}$. Fentanyl merupakan suatu obat yang mempunyai sifat sangat lipofilik dan dapat menembus sawar darah otak dengan cepat sehingga pemakaian fentanyl melalui intravena akan memberikan efek analgetik dengan segera. Hampir sama dengan morfin, fentanyl menghasilkan analgesik kuat untuk pembedahan, menimbulkan depresi pernafasan, bradikardia, mual, dan muntah. Akan tetapi, berbeda dengan morfin, fentanyl mempunyai mula kerja yang cepat, masa kerja singkat, efek mual muntah sedikit, dan relatif tidak berpengaruh pada sistem kardiovaskuler. Fentanyl merupakan narkotik pilihan pertama untuk neuroanestesia. Penggunaan fentanyl sedikit menurunkan ICP dan mempertahankan CPP lebih baik daripada sufentanil. Fentanyl menurunkan resistensi absorpsi cairan serebrospinal dan menyebabkan penurunan volume darah otak sebesar $10 \%$. Pada dosis tinggi $(>5 \mu \mathrm{g} / \mathrm{kg})$ fentanyl menurunkan minimum alveolar concentration (MAC) sebesar $65 \%$. Dosis yang lebih kecil, lebih cocok untuk bedah saraf dan tidak banyak menurunkan MAC. ${ }^{5}$

\section{Diuretik}

Pada kasus ini pasien diberikan mannitol 15 menit sebelum duramater dibuka. Penggunaan diuretik osmotik seperti mannitol akan meningkatkan osmolaritas darah secara akut, sehingga mengurangi kandungan air otak. ${ }^{1}$ Mannitol juga digunakan intraoperatif untuk menginduksi relaksasi otak pada tindakan reseksi tumor otak. 
Mannitol umumnya diberikan intravena pada dosis 0,25 sampai $1,5 \mathrm{~g} / \mathrm{kgBB}$ pada pasien yang menjalani kraniotomi. Dosis mannitol lebih tinggi memberikan relaksasi otak yang lebih baik tetapi efek samping yang ditimbulkan juga lebih berat. Menimbang antara keuntungan dan kerugian dari pemberian mannitol, peneliti menyarankan penggunaan dosis $1,0 \mathrm{~g} / \mathrm{kgBB}$ intraoperatif mannitol untuk relaksasi otak yang memuaskan dengan efek samping yang lebih sedikit. ${ }^{7}$ Pada pasien ini mannitol diberikan dengan dosis 1 $\mathrm{g} / \mathrm{kgBB}$ (digunakan $300 \mathrm{ml}$ mannitol 20\%) intravena.

\section{Manajemen Anestesi}

\section{Penilaian Preoperatif}

Evaluasi pra operasi diperlukan untuk mengevaluasi keadaan pasien dan karakteristik saluran napas. Ahli bedah saraf harus menjelaskan kelebihan, kebutuhan, dan sifat dari prosedur. Dalam hal operasi tumor, diagnosis patologis yang paling umum pada pasien yang menjalani awake craniotomy adalah low grade glioma, namun, high grade glioma, metastasis ke otak, dan meningioma dengan letak dekat reseksi korteks fungsional juga sering direncanakan memakai teknik awake craniotomy. Evaluasi preoperasi harus mempertimbangkan aspek-aspek berikut:

1. Saluran nafas atas: prediksi intubasi trakea yang sulit (konformasi fisik dan intubasi sebelumnya); risiko obstruktif apneu (obesitas, sleep apnea, retrognathia).

2. Epilepsi: farmakoterapi; konsentrasi serum obat antiepilepsi; jenis dan frekuensi kejang.

3. Mual dan muntah: anestesi sebelumnya; kinetosis.

4. Perkiraan tekanan intrakranial: jenis lesi; tanda-tanda radiologis dan klinis.

5. Risiko perdarahan: jenis dan lokalisasi lesi; terapi (obat antiplatelet); riwayat kesehatan.

6. Kerja sama pasien: kecemasan; toleransi nyeri; defisit neurologis.

Evaluasi jalan napas preoperatif sangat penting mengingat kesulitan mengelola komplikasi saluran napas selama prosedur. Sleep apnea syndrome harus dipertimbangkan sebagai kriteria eksklusi absolut. Evaluasi edema otak juga penting, karena jauh lebih sulit untuk mengontrol tekanan intrakranial selama pernapasan spontan dibandingkan dengan ventilasi mekanis. Pasien epilepsi juga harus dievaluasi secara seksama karena kejang yang tidak terkendali adalah kriteria eksklusi relatif untuk awake craniotomy. Terjadinya kejang akibat stimulasi intraoperatif mungkin terkait dengan konsentrasi serum obat antiepilepsi yang rendah, teknik stimulasi, dan rejimen anestesi (opioid dosis tinggi dan neuroleptik). Menariknya, menurut Szelényi, pasien dengan epilepsi simtomatik tidak tampak memiliki risiko lebih tinggi terhadap stimulasi intraoperatif yang terkait dengan kejang dibandingkan pasien tanpa epilepsi simtomatik selama keadaan awake.

Akhirnya, kerjasama dan partisipasi pasien yang lengkap sangat diperlukan untuk prosedur ini. Disfasia dan kebingungan yang besar adalah kriteria eksklusi absolut. Terkait pemilihan pasien dan strategi intraoperatif, pada tahun 2006 Picht et al. mengusulkan protokol multimodal yang menarik untuk awake craniotomy dalam bedah tumor korteks pada pusat bahasa: mengikuti pemetaan kortikal, prosedur dilanjutkan dengan anestesi umum sesuai dengan status klinis pasien dan hasil gabungan pemetaan otak dan pencitraan resonansi magnetik fungsional (fMRI). Sebelum operasi, pasien harus diberitahu tentang risiko potensial, tindakan keamanan, tahapan prosedur, dan apa yang akan terjadi ketika dia berada di ruang operasi. Kunjungan ke ruang operasi sebelum operasi adalah ide yang baik untuk membiasakan pasien dengan suara dan peralatan di kamar. Ahli anestesi harus mendapatkan kepercayaan pasien, karena pasien akan bergantung padanya selama prosedur. $^{8}$

\section{Persiapan Preoperatif}

Pemberian edukasi kepada pasien maupun keluarga sebelum operasi pada pasien yang akan menjalani awake craniotomy sangat penting agar mengurangi kecemasan dan pasien kooperatif selama pembedahan. Sebelum operasi pasien diinformasikan bahwa lesi yang akan dioperasi melibatkan pusat bahasa dan bicara sehingga saat operasi ada periode pasien akan bangun namun terbebas dari rasa nyeri. ${ }^{3}$ 


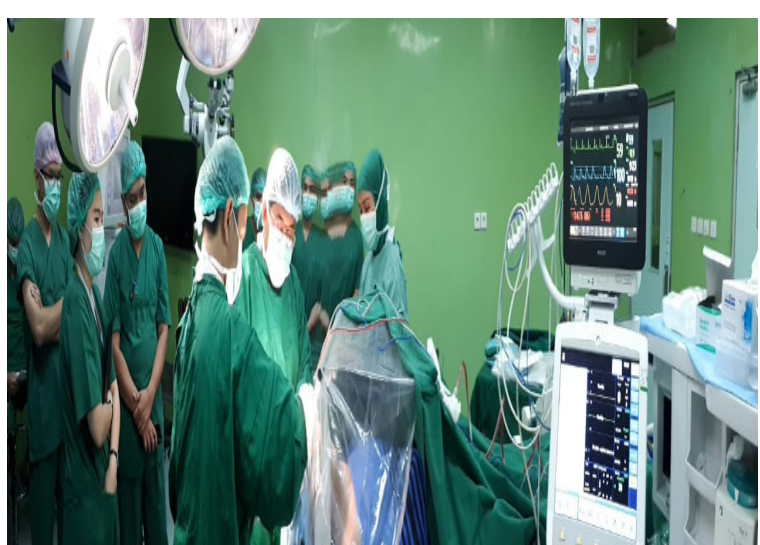

Gambar 2. Posisi Operator dan Suasana pada saat Awake Craniotomy

\section{Premedikasi}

Pada pasien tumor tanpa disertai gejala peningkatan tekanan intrakranial (TIK) dapat diberikan benzodiazepine dosis kecil misalnya alprazolam $0,5 \mathrm{mg}$ peroral malam hari untuk mengurangi kecemasan. Pasien harus terhindar dari stress (akan meningkatkan Cerebral Metabolic Rate dan Cerebral Blood Flow/CBF) dan hipertensi (akan meningkatkan $\mathrm{CBF}$, yang juga dapat menimbulkan edema vasogenik dengan kegagalan autoregulasi). Pemberian sedasi di ruangan perawatan dapat menyebabkan risiko hiperkapnia, hipoksemia, dan obstruksi partial jalan nafas sehingga dapat meningkatkan TIK. ${ }^{1}$ Pada pasien ini tidak diberikan benzodiazepine di ruangan perawatan tapi diberikan midazolam 2 mg iv saat pasien masuk kamar operasi.

Pada pasien ini juga diberikan steroid dexametason $10 \mathrm{mg}$ iv dan ondansetron 4 $\mathrm{mg}$ iv di kamar operasi sebagai antiemetik selama pasien terbangun saat operasi. Hipotermia dan menggigil harus dicegah dengan penggunaan selimut, perangkat udara hangat, dan suhu ruangan yang sesuai. Tramadol $50 \mathrm{mg}$ atau meperidine $25 \mathrm{mg}$ hingga $30 \mathrm{mg}$ intravena mungkin efektif untuk mencegah menggigil. ${ }^{9}$

\section{Akses Vaskuler}

Dua jalur intravena perifer dipasang pada pasien ini dengan needle nomor 20 (satu dipasang pada tangan saat pasien di ruang perawatan, dan satu lagi dipasang pada kaki saat pasien sudah di ruang operasi). Pada pasien ini tidak dipasangkan akses vena sentral. Akses vena sentral diindikasikan bila secara klinis ada potensi terjadinya emboli udara.

\section{Monitoring}

Standar monitor termasuk EKG, tekanan darah non invasif, pulse oksimetri. Tekanan darah invasif tidak perlu begitu juga dengan monitor central venous pressure (CVP) tidak perlu, dengan pengecualian bila ditakutkan adanya emboli udara maka dipasang kateter vena sentral. Oksigen diberikan melalui face mask atau kanul binasal, dan lebih disukai pemakaian kanul binasal karena lebih nyaman untuk pasien dan dapat bebas berbicara. Bila dilakukan test bicara, lebih mudah untuk dokter anestesi untuk melihat muka pasien untuk melihat setiap gejala kejang. ${ }^{2}$

\section{Memposisikan Pasien}

Posisi supine baik, untuk memudahkan melihat muka pasien dan membebaskan jalan nafas. Penting bahwa pasien harus bisa melihat dokter anestesi dan dokter anestesi harus bisa melihat pasien. Penempatan posisi kepala tergantung dari dokter bedah sarafnya. Posisi pasien harus memudahkan pasien menggerakan tangan atau kakinya. Pemasangan pin holder merupakan stimulus nosiseptik terkuat. Hal tersebut harus dibarengi dengan blokade nyeri yang adekuat. Sebelum dipasangkan pin holder, injeksi infiltrasi larutan Bupivacain-pehacain tambahan diberikan 2,5-3 ml pada setiap tempat penusukan pin dan pemberian analgesia kuat (bolus fentanyl $1 \mathrm{mcq} /$ kgbb) untuk mencegah perburukan SSP yang tidak diinginkan dan aktivasi hemodinamik. ${ }^{1}$

\section{Penilaian Status Neurologik Pasien}

Segera sebelum reseksi tumor, pasien dibangunkan dengan menghentikan propofol kira-kira 10 menit dilakukan tes (motorik dan bicara), sedangkan dexmetodemidine tetap diberikan, sehingga dapat berkomunikasi dengan dengan anesthesiologist dan ahli bedah. Pasien kemudian diminta untuk melakukan tugas verbal dan visual untuk memfasilitasi identifikasi area bicara selama stimulasi. Pada pasien setelah situs bahasa diidentifikasi, margin reseksi diambil dalam 1 hingga $2 \mathrm{~cm}$ area kortikal yang 
penting untuk fungsi bicara. Pada pasien yang motor utama dan korteks sensorik dipetakan, margin reseksi diambil lebih dekat ke margin kortikal (hingga $0,5 \mathrm{~cm}$ ). Reseksi dihentikan jika fungsi bicara memburuk tetapi dilanjutkan jika pemulihan penuh terjadi dalam 5 menit. Selama stimulasi kortikal, perekaman simultan menggunakan elektrokortikografi tidak dilakukan karena pembukaan kraniotomi disesuaikan pada pasien ini. ${ }^{10}$

\section{Simpulan}

Awake Craniotomy adalah teknik yang penting digunakan untuk eksisi tumor otak pada area korteks bahasa. Manajemen anestesi yang tepat sangat berguna agar tindakan evakuasi massa bisa dilakukan secara optimal dan pasien bisa terbebas dari rasa nyeri. Kombinasi anestesi intravena dengan dexmedetomidine dan blok scalp dapat menjadi pilihan dalam awake craniotomy

\section{Daftar Pustaka}

1. Lalenoh DC, Lalenoh HJ, Rehatta NM. Anesthesia for craniotomy supratentorial Tumor. Jurnal Neuroanestesia Indonesia. 2012;1(1).

2. Bisri T. Awake craniotomy can be done humanly? JKA; 2013; 1(1): 73-80.

3. Burnand C, Sebastian J. Anaesthesia for awake craniotomy. Continuing in Anasthesia, Critical Care \& Pain, 2014; 4(1).

4. Mahajan C, Rath GP, Singh GP, Mishra $\mathrm{N}$, Sokhal S, Bithal PK. Efficacy and safety of dexmedetomidine infusion for patients undergoing awake craniotomy:
An observational study. Saudi J Anaesth. 2018;12(2):235-9.

5. Bisri DY, Bisri T. Awake Craniotomy: pengalaman dengan dexmedetomidin. Jurnal Neuroanestesi Indonesia. 2015;4(3):212-22.

6. Prihatno MMR, Harahap MS, Akbar IB, Bisri T. Penurunan kadar glutamat pada cedera otak traumatik pasca pemberian agonis adrenoseptor alpha-2 dexmedetomidin sebagai indikator proteksi otak. Jurnal Neuroanestesia Indonesia. 2014 ; 3(2):69-9.

7. Se H, Kim E, Jung H, Lim YJ, Kim JW, Park $\mathrm{CK}$, et al. A prospective randomized trial of the optimal dose of mannitol for intraoperative brain relaxation in patients undergoing craniotomy for supratentorial brain tumor resection. J Neurosurg. 2017; $126(6): 1839-46$.

8. Piccioni F, Fanzio M. Management of anesthesia in awake craniotomy. Minerva Anestesiol. 2008;74(7-8):393-408.

9. Zhang K, Gelb AW. Awake craniotomy: indications, benefits, and techniques. Rev Colomb Anestesiol. 2018;46:46-51.

10. Kim SS, McCutcheon IE, Suki D, Weinberg JS, Sawaya R, Lang FF, et al. Awake craniotomy for brain tumors near eloquent cortex: correlation of intraoperative cortical mapping with neurological outcomes in 309 consecutive patients. Neurosurgery. 2009;64(5):836-46. 